\title{
Sustainable independent tourism: the role of the information and communication technologies
}

\author{
Olga Sutyrina ${ }^{1 *}$, Svetlana Domracheva ${ }^{2}$, Natalia Okhotina $^{3}$, and Yana Pavlova ${ }^{4}$ \\ ${ }^{1}$ Management and Law Department, Labortory of Interethnic and Interconfessional Studies, Faculty of \\ Management and Law, Volga State University of Technology, Lenin square 3, Yoshkar-Ola, 424000, \\ Russian Federation \\ ${ }^{2}$ Department of Developmental Psychology and Education, Pedagogical Institute, Mari State University, \\ Lenin square 1, Yoshkar-Ola, 424000, Russian Federation \\ ${ }^{3}$ Department of Service and Tourism, Faculty of Social Studies, Volga State University of Technology, \\ Lenin square 3, Yoshkar-Ola, 424000, Russian Federation \\ ${ }^{4}$ Department of Small and Medium Business Management, Institute of Digital Technologies, Mari State \\ University, Lenin square 1, Yoshkar-Ola, 424000, Russian Federation
}

\begin{abstract}
This paper focuses on the role of information and communication technologies (ICT) in the sustainable independent tourism and hospitality. Moreover, it attempts to identify emerging trends in tourism of the $21^{\text {st }}$ century. Nowadays, tourism has become more independent on large travel agencies and package tours and this transition has been caused by the development of Internet and information technologies. Most recently, the rise of the sharing economy had an array of important implications for the tourism sector with such digital platforms as Uber, Airbnb, Gett, Lyft, TripAdvisor, Expedia or Booking.com replacing the traditional ways to travel. Surely, independent tourism is not for everyone and might be restricted to small groups of people. However, it is crucial for sustainable development in tourism and hospitality sector due to the fact that it can replace massive tourism and limit the extent of overtourism in many popular destinations.
\end{abstract}

\section{Introduction}

Tourism can bring great benefits to local communities, as it provides sustainable livelihoods, employment and additional income [1]. The tourism literature looks at tourism phenomenon and examines the impact of tourism on social and economic development and on the local economy. It also identifies globalisation as the factor that has an impact on the social and economic development of people worldwide and their travel needs $[2,3]$.

Information and communication technologies (ICT) changed the way tourism industry is explored by the millennials and post-millennials in selecting and organising their tourist experience, as well as the importance that is attributed to the holiday and its more frequent practice [4]. Nowadays, there are new strategies that the tourism industry should implement to meet the needs of tourists proficient in ICTs.

\footnotetext{
*Corresponding author: Sutyrina.olya@yandex.ru
} 
Entwined into the computer terminology, sustainable independent tourism can refer to a new form of tourism characterised by changes in its fundamental characteristics. Recent surveys of members of generations $\mathrm{Y}$ and $\mathrm{Z}$ confirm that the rise of the Internet is eroding the model of mass tourism $[5,6]$. In a way, modern tourism is much more than a simple journey and it can have a positive or negative impact on various aspects. Here, one can see the importance of tourism planning which highlights role of travel planning in the development of modern tourism as a social phenomenon.

Today, there is a strong correlation between the rise of the Internet and the decline of mass tourism. Once, the Internet was considered to be a crucial factor in developing of tourism. Tourism is an important industry and a strong economic vehicle that makes a significant contribution to the national economy as a whole. When researchers examine the social and economic impact of tourism on the development of society, a demonstration effect is introduced into tourism [7]. This is why it comes into play - by depending on the strength of a region, tourism can have positive or negative effects on social development in different parts of the world. Tourism is also accused of harming the young members of the host community, which could mimic the behaviour of tourists and affect traditional values. Moreover, demonstrating this effect implies that culture is weak and needs to be protected from external influences. It is also noticeable that people are more interested in leisure activities such as shopping and eating than in traditional activities.

These processes, activities and results are the consequences of the interaction between the tourist and the environment responsible for transporting tourists and other visitors, as well as their interaction with the locals. In short, today tourism is not just an industry, but an open, dynamic and complex system. Sustainable development of tourism is subject to many factors and influences many other factors, such as economic, environmental, cultural and social aspects [8].

\section{Online booking system and independent tourism}

Tourism and travel industry have been revolutionized in recent years by the software community, with the emergence of online booking systems such as TripAdvisor and Booking.com. Travel agencies have been creating travel websites for their customers since the early 1990s, often in cooperation with other travel agencies and travel companies. Today's travel agents, which have Internet access and traditional dial-up connections, are widely used by the majority of airlines for their use in global travel. Priceline.com "The Go" has become a bestseller providing a destination for multi-legged bookings. While most travellers can search their itineraries themselves, most of them still rely on travel agencies to book trips for large groups, or those with different schedules, or to travel with a large group or other schedule [9]. Online bookings have undergone several minor improvements in recent years, which are generally related to general technical progress.

In addition, online banking and online payment systems have become much more secure, offering faster processing and even transactions with cryptocurrencies [10]. With the rising popularity of smartphones and usual mobile applications, leisure customers can now plan a week-long journey in minutes or rent a car with just a few simple steps. There are multiple computer systems used to store and retrieve information and those used for related transactions such as credit card transactions. Most airlines have outsourced their sales to the online companies, which also provide consumers with access via Internet gateways. Although originally conceived and operated by the airline, ticket booking is now being extended to other companies such as travel agencies, hotels, airlines and hotel chains [11].

Online reservation systems thus offer an ideal system for travel agencies, tourists and carousel drivers to plan their itineraries. Typically, modern global distribution systems (GDSs) allow users to book hotels, restaurants, hotels and other hotels within the same city 
or region, as well as other destinations. Currently, there are many hotel reservation software that has been developed and maintained to make reservations easy and convenient for consumers. Various online booking systems allow websites to simplify reservation systems which were not the case a decade ago. However, competition and unexpected growth in the hospitality industry has enabled software developers to provide additional services with additional features such as booking software to meet the needs of the hotel management system. The latter has encouraged innovation in software, and currently there is a wide range of online reservation systems for hotels and restaurants [12]. All mentioned above has made hotel reservation system be conveniently located at the hotel reception, with an integrated online booking system or a mobile app.

A small division of Microsoft called Expedia launched its website, which offered a range of online booking systems for hotels, restaurants, hotels and travel agencies in 1996. Viator Systems (now Viators) was founded with the aim of offering tour and excursion bookings on the World Wide Web. Full integration of property management systems (PMS) into hotels means that the distribution system used to connect more travel agencies around the world is cost-effective and hassle-free. As several agencies surf from a single access point, hotels also benefit from improved market access, consequently, this makes travel bookings more efficient and efficient.

There are many online booking engines that offer dedicated travel websites allowing potential customers to book flights and unique content and products [13]. The booking engines combine the look and feel of a travel business website with the functionality of the most advanced travel booking system available on the market. Travel companies handle flight bookings with travel agent software and travel agencies in other hospitality industries - related initiatives such as hotels, restaurants and hotels. A travel booking software is now seen as an integrated system to improve the opportunities for customers to use online portal for booking travel tickets. A travel agent's software should provide the customer with access to a wide range of online ticket and travel booking services. With multiple distribution channels and functions, a travel agent's system can be used for a wide range of different sales types, from direct sales to direct marketing, though it should ultimately be flexible. Internet booking engines allow tourists to manage complex packages such as travel tickets, hotel rooms, flights and much more by themselves, thus without going to large tourist agencies and package tours providers. They can also manage production and complex packaging simply by using dynamic packaging with the customer's own resources. Therefore, people are able to plan their travels independently, thus causing less harm to the environment and reducing the impacts of the so-called "overtourism" [14].

\section{Sustainable sharing economy in tourism and hospitality}

The sharing economy, also known as peer-to-peer (P2P) sharing, is a concept that emphasizes the ability for people to rent or borrow goods and services rather than buy or own them [15]. This has confused the idea of sharing with potential consumers who opt for joint transactions instead. For companies that may have been disadvantaged as a result of the growth of the sharing economy, this has opened the door for SMEs (independent ad hoc young entrepreneurs) to benefit from sharing their services and assets. According to thepeoplewhoshare.com, the sharing economy is one of the ten building blocks that make up a sustainable ecosystem. One of the best examples of a sharing economy giant, Airbnb is valued at billions of dollars as a scrap-metal start-up that embodies the eco-chic principles of the sharing economy. The decentralized business model has spread Airbnb's environmental impact around the world and disguised the company's true footprint. The entire experience of the guest is inherently lavish, from the breakfast buffet to frequent laundry washing to the breakfast buffet and bed linen and cleaning. 
With the growth of the sharing economy, more opportunities will be available to travellers, potentially creating new opportunities for sustainable tourism and healthcare in the tourism industry. As the economy grows, so does its impact on the environment and on the health and safety of travellers [16]. An interesting speculation is that the sharing economy could lead consumers to buy more expensive products that are more durable and possibly more environmentally friendly, in order to monetize the untapped potential of these goods. Many of the statistics mentioned in this article are from the World Economic Forum's 2015 Sustainable Tourism and Health Report. Companies large and small are using peer-to-peer technology in ways that could prove much greener in the long run. Electric cars are cited as an example in the 2015 World Economic Forum report on sustainable tourism and health, and sharing-economy companies such as Airbnb, Uber, and Lyft have cited the environmental benefits of their products [17]. Better use of these products is probably the most important and vaguely quantified environmental benefit of this new technology. In some sectors, the exact costs and revenues are not yet clear, and while these new trends are problematic for the tourism industry, they do not appear to be. On the other hand, the development of quality in 3D printing technology offers great opportunities for tourism and the hospitality industry. The development of digitalisation has reached a level where it can be truly supported and paves the way for a future for tourism and hospitality [18].

The impact of Airbnb on the sustainability of the hospitality and tourism industries in the United States is vast. According to some estimates, Airbnb is used by more than 2.5 million people, or about one-third of all visitors to the United States each year. However, the key questions are how the conventional hospitality industry would respond to the new offers and changing requirements. In addition, how the sharing economy would assume relevance in the context of the changing form of tourism and its impact on the hospitality industry. Current trends in urban tourism need to be analysed with a special focus on potential spatial effects. These changing and emerging forms of tourism are probably going to affect the real estate market in cities and counties. In many cases, the sharing economy depends on users' will to share, and this sharing makes it difficult for users to conquer strange dangers. Thus, one should be thinking of developing technological solutions such as the new personal data consent service that would help users trust their services and improve the trust of their customers. This will also allow users to better control what happens to their data and confirm the identity of other consumers in the shared economy. A 2015 study by PricewaterhouseCoopers looked at the economic impact of the sharing economy on tourism and healthcare in the UK. It states that growth estimates remained sparse and were difficult to assess due to a lack of data on the number of transactions in the shared economy and the nature of those transactions [19].

\section{Independent tourism and ICT}

In the digital age, do-it-yourselves who plan their journey online are increasingly relying on the internet to find out about travel options. Tour operators have suffered from the rise of independent tour operators and are now using online and mobile channels to stay competitive. While many travel agents in the upper price brackets have been killed by the Internet, while many have taken it on with the introduction of online bookings, others are being forced to adapt to a very changing market.

The necessary information transmitted and displayed to tourists is also the means of communication technology. Communication technology has a paramount role in the tourism industry, as it is an essential part of the service and business process. Travel technology, also known as tourism technology or automation of the hospitality industry, is an important part of the travel industry and a key element in the development of the tourism industry [20]. Another form of travel technology is the possibility to plan a trip online or through travel 
agencies. Some of them have online reservation features on the official company website, and some have them on their own website. Although the role that ICT can play in making an organisation competitive and standing out from the rest was recognised many years ago, the potential it offers has only recently been recognised in the tourism and hospitality industry. It has deep roots in the past, present and future impacts of the use of technology in tourism, hospitality, tourism industry and travel industry in general. In short, ICT is considered essential for the success or failure of tourism and will have a significant impact on virtual tourism and on the management of tourism and hospitality, as it will become easier. The activities in the field of ICT in tourism aim at developing a distributed architecture that can support both users and businesses by offering added value - services. Indeed, there is a strong correlation between the use of information and internet technologies and the development of travel technology.

Today's business and tourism market is characterised by the use of the Internet as a means of communication between companies and their customers. Organizational and sales costs can be reduced by distributing products and services more efficiently and by creating new business models. In addition, digital interactions introduce new forms of social interaction and bonding and enable the development of virtual communities. These features of the technology are changing the landscape of mediation in the tourism process and strengthening new - fashionable - web-based mediators and their customer base. New intermediaries are being created on the Internet, and traditional ones must change their roles. More and more tourism companies are combining their business with web services, and web-based platforms are also part of the development of personal and virtual identities. Finally, the use of digital content based on social networks such as Facebook, Twitter, Instagram and YouTube enable new forms of social interaction and retention, as well as the exchange of knowledge and information. With digitised content widely available, it transforms what has been largely a private social experience and knowledge exchange into a global database of consumer information that tourism companies and organisations can manage and analyse, contributing to the growth of sustainable tourism and tourism businesses.

\section{Conclusions}

In the end, emergence of various technologies, such as the Internet, tablets, computers, and cell phones has much influenced the way people communicate. Digital innovations in communication and technological media have advanced the metamorphosis of traditional categories of knowledge and culture and have redefined the perception and practical experience of tourism.

The ICT and tourism activities aim to develop a distributed architecture that supports both users and businesses and provides added value, with a focus on virtual reality and augmented reality experiences. But most importantly it can considerably limit massive tourism and cut the volume of overtourism in many popular tourist destinations. This process is very important for cutting the $\mathrm{CO}_{2}$ emissions from global air travel and the reduction of greenhouse gases, which would in turn lead to the sustainable development in tourism and hospitality sector.

Sustainable tourism is facing various challenges, while the way to achieve the state of sustainability is long and winding. The anticipated though a bit confusing blockchain technology would help halt some challenges in sustainable tourism development and address its goals. Literally, the blockchain technology might potentially rattle tourism operations and advance local economy, organize food supply chain in a more efficient way, by alleviating food waste, satisfy tourists, and alter the tourists' sustainable attitude and performance. One might argue that the future is deemed to artificial intelligence (AI), that would have the highest impact on tourism industry as well as tourist behaviour. So far, artificial intelligence 
has already influenced the way tourists behave and different tourist enterprises operate. But that may be a subject of a different research paper.

\section{References}

1. B. Chen, Z.Qiu, N. Usio, K. Nakamura, Sustainability, 10(8), 2896 (2018)

2. A. Chiabai, S. Platt, W. Strielkowski, Tourism Economics, 20(2), 263-277 (2014)

3. M. A. Casado-Diaz, A. B. Casado-Díaz, G. Hoogendoorn, Scandinavian Journal of Hospitality and Tourism, 20(3), 268 (2020).

4. L. Zhenhua, Sustainable Tourism Development: A Critique, Journal of Sustainable Tourism, 11(6), 459 (2003)

5. L. Clifford, K. Nelson, R. Black, Journal of Hospitality and Tourism Management, 46, $96(2021)$

6. S. Monaco, Journal of Tourism Futures, 4(1), 7 (2018),

7. S. Leminen, M. Rajahonka, M. Westerlund, R. Wendelin, Journal of Business \& Industrial Marketing, 33(6), 749 (2018)

8. D. Fisher, Annals of Tourism Research, 31(2), 428 (2004)

9. P. Aditjandra, Advances in Transport Policy and Planning, Academic Press, 3, 29 (2019)

10. J.Y. Lee, Business Horizons, 62(6), 773 (2019)

11. A. Polukhina, A.Tarasova, A.Arnaberdiyev, International Journal of Recent Contributions from Engineering Science \& IT (iJES), 8(1), 81 (2020)

12. S. Mercan, L. Cain, K. Akkaya, M. Cebe, S. Uluagac, M. Alonso, C. Cobanoglu, International Journal of Contemporary Hospitality Management, 33(1), 243 (2020)

13. D. Buhalis, T. Harwood, V. Bogicevic, G. Viglia, S. Beldona, C. Hofacker, Journal of Service Management, 30(4), 484 (2019)

14. Lundmark L., Carson D.A., Palgrave Macmillan, Singapore (2020)

15. B. Parguel, R. Lunardo, F. Benoit-Moreau, Technological Forecasting and Social Change, 125, 48 (2017)

16. D. Selloni, CoDesign for Public-Interest Services. Research for Development. Springer, Cham. (2017)

17. J.I. Pulido-Fernández, L. Andrades-Caldito, M. Sánchez-Rivero, Journal of Sustainable Tourism, 23(1), 47 (2015)

18. D. Miller, B. Merrilees \& A. Coghlan, Journal of Sustainable Tourism, 23(1), 26 (2015)

19. M. Klöckner, S. Kurpjuweit, C. Velu, S.M. Wagner, Research-Technology Management, 63(4), 18 (2020)

20. PWC, https://www.pwc.com/hu/en/kiadvanyok/assets/pdf/sharing-economy-en.pdf (2015) 